\section{JURNAL ABDIMAS

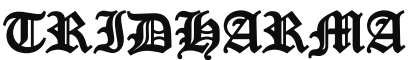 \\ AtA}

P-ISSN 2615-6849, E-ISSN 2622-3686

Jurnal ABDIMAS Vol. 1,No. 3,September 2020,Hal (28-32)

@Prodi Manajemen Fakultas Ekonomi Universitas Pamulang

Email: abdimasjurnal.unpam@gmail.com Telp: (021) 741-2566

\title{
PENGENALAN DAN PENGEMBANGAN KOMPETENSI KARYAWAN AGAR MENCAPAI SASARAN ORGANISASI
}

\author{
Jublina Oktora, Gatut D. Purwoko, Muhammad Arief, Muhammad Gandung, \\ Syawaludin \\ Dosen Magister Ekonomi Universitas Pamulang \\ Email : dosen01887@unpam.ac.id, dosen00612@unpam.ac.id, \\ dosen02304@unpam.ac.id , dosen02020@unpam.ac.id, dosen02298@unpam.ac.id
}

\begin{abstract}
ABSTRAK
Tujuan dari pelaksanaan Pengabdian Kepada Masyarakat yang berjudul "Pengenalan dan Pengembangan kompetensi karyawan agar mencapai sasaran organisasi" adalah sebagai upaya pemenuhan kewajiban Tri Dharma Perguruan Tinggi. Pengabdian Kepada Masyarakat dilakukan di Kelurahan Rempoa, beralamat di Jl. Pahlawan, Ciputat Timur, Banten. Dalam jangka waktu 3 hari terhitung mulai tanggal 20 April sampai dengan 22 April 2020.

Berdasarkan hal di atas, kegiatan pengabdian kepada masyarakat yaitu memberikan informasi dan atau tambahan pengetahuan mengenai pengembangan kompetensi karyawan khususnya karyawan kelurahan Rempoa dalam rangka peningkatan kompetensi karyawan untuk meningkatkan pelayanannya kepada masyarakat dan menggunakan teknologi di kelurahan Rempoa merupakan suatu hal yang bermanfaat. Selain itu juga sebagai wujud eksistensi Perguruan Tinggi yang bertujuan untuk memberikan konstribusi besar kepada pengembangan dan penerapan ilmu kepada masyarakat.

Metode yang digunakan pada Pengabdian Kepada Masyarakat ini berupa penyampaian materi secara ceramah dan pembelajaran yang menekankan pada proses simulasi yaitu suatu bentuk pelatihan dan pengembangan karyawan yang menggunakan suatu alat mekanikal yang identik dengan alat yang akan digunakan oleh peserta pelatihan dan pengembangan dalam tugasnya.
\end{abstract}

Kata Kunci : Pengabdian, Pengembangan Kompetensi, Teknologi

\section{ABSTRACT}

The purpose of the implementation of Community Service entitled "The Introduction and Development of Employee Competencies In Order To Achieve Organizational Goals" is as an effort to fulfill the obligations of the tri dharma of higher education. Service to the community is done in the village of Rempoa, located in Jl. Pahlawan, Ciputat Timur, Banten. Within a period of three days, starting from April 20 to April 22, 2020.

Based on the above, community service activities, namely providing information and or additional knowledge regarding the development of employee competencies, especially employees in Kelurahan Rempoa in the context of increasing employee competence to improve their services to the community and using technology in Kelurahan Rempoa is beneficial. In addition, it is also a form of the existence of higher education institutions that aim to make a major contribution to the development and application of knowledge to the community.

The method used in this community service is the delivery of material in lectures and lessons that emphasize the simulation process, which is a form of training and employee development that uses a mechanical device that is identical to the tool that 


\section{JURNAL ABDIMAS

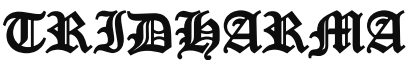

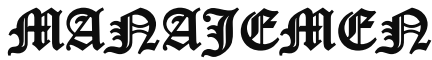

P-ISSN 2615-6849, E-ISSN 2622-3686

Jurnal ABDIMAS Vol. 1,No. 3,September 2020,Hal (28-32)

@ Prodi Manajemen Fakultas Ekonomi Universitas Pamulang

Email: abdimasjurnal.unpam@gmail.com Telp: (021) 741-2566

will be used by training and development participants in their assignments. As a result employees have increased competence and use of technology.

Keywords: Service, Competency Development, Technology

\section{PENDAHULUAN}

Pengalaman banyak organisasi menunjukkan, bahwa dengan menyelenggarakan program pengenalan dan pengembangan karyawan yang sangat komprehensif sekalipun, belum tentu menjamin bahwa para karyawan baru serta merta dapat melaksanakan tugas dengan memuaskan. Artinya para karyawan baru itu masih memerlukan pelatihan dan pengembangan tentang berbagai tugas pekerjaan yang dipekerjakan kepada mereka. Para karyawan yang sudah berpengalaman pun selalu memerlukan peningkatan pengetahuan, keterampilan dan kemampuan karena selalu ada cara yang lebih untuk meningkatkan produktivitas kerja. Belum lagi kalau seseorang karyawan ditempatkan pada tugas pekerjaan yang baru.

Oleh karena itu diperlukan adanya pengembangan kompetensi karyawan. Hal ini akan bermanfaat bagi organisasi dan bagi para anggota organisasi. Bagi suatu organisasi terdapat manfaat dalam menyelenggarakan program pengembangan tenaga kerja, antara lain:

1. Peningkatan produktivitas kerja organisasi sebagai keseluruhan antara lain karena tidak terjadinya pemborosan, karena kecermatan melaksanakan tugas, tumbuh suburnya kerjasama antara berbagai satuan kerja yang melaksanakan kegiatan yang berbeda dan spesialistik, meningkatkan tekad mencapai sasaran yang telah ditetapkan serta lancarnya koordinasi sehingga organisasi bergerak sebagai suatu kesatuan yang butuh dan utuh.

2. Terwujudnya hubungan yang serasi antara atasan dan bawahan, antara lain adanya pendelegasian wewenang, interaksi yang didasarkan pada sikap dewasa baik secara teknikal maupun intelektual, saling menghargai dan adanya kesempatan bagi bawahan untuk berpikir dan bertindak secara inovatif.

3. Terjadinya proses pengambilan keputusan yang lebih cepat dan tepat karena melibatkan para karyawan yang bertanggung jawab menyelenggarakan kegiatankegiatan operasional dan tidak sekedar diperintah oleh para manajer.

4. Meningkatkan semangat kerja seluruh tenaga kerja dalam organisasi dengan komitmen organisasional yang lebih tinggi.

5. Mendorong sikap keterbukaan manajemen melalui penerapan gaya manajerial yang partisipatif.

6. Memperlancar jalannya komunikasi yang efektif yang pada gilirannya memperlancar proses perumusan kebijaksanaan organisasi dan operasionalistik.

7. Penyelesaian konflik secara fungsional yang dampaknya adalah tumbuh suburnya rasa persatuan dan suasana kekeluargaan di kalangan para anggota organisasi.

Lalu kompetensi-kompetensi apakah yang dibutuhkan oleh profesional sumber daya manusia (SDM)? Para profesional SDM harus memiliki enam kompetensi yang diidentifikasi oleh Human Resource Competency Study, dimana tampilan kompetensi-kompetensi tersebut dapat membantu para profesional SDM untuk menunjukkan kepada para manajer bahwa mereka mampu membantu fungsi SDM dalam menciptakan nilai, memberikan kontribusi terhadap strategi bisnis dan membentuk budaya perusahaan. Enam kompetensi bagi profesional SDM

Sebagai bagian dari peran strategisnya, salah satu kontribusi utama 


\section{JURNAL ABDIMAS

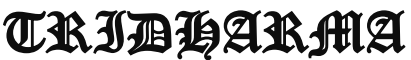

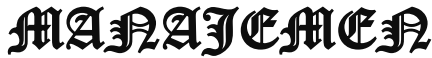

P-ISSN 2615-6849, E-ISSN 2622-3686

Jurnal ABDIMAS Vol. 1,No. 3,September 2020,Hal (28-32)

@ Prodi Manajemen Fakultas Ekonomi Universitas Pamulang

Email: abdimasjurnal.unpam@gmail.com Telp: (021) 741-2566 yang dapat dibuat oleh Departemen SDM adalah keterlibatannya pada SDM berbasis bukti. SDM berbasis bukti (evidencebased $H R$ ) menunjukkan bahwa praktikpraktik SDM memiliki pengaruh positif terhadap target perusahan / organisasi atau para pemangku kepentingan (para karyawan, pelanggan, masyarakat dan pemegang saham). Hal tersebut akan membantu menunjukkan bahwa uang yang diinvestasikan dalam programprogram SDM dapat kita benarkan dan SDM memberikan kontribusi penting terhadap sasaran dan tujuan perusahaan / organisasi. SDM berbasis bukti membutuhkan pengumpulan data metrik seperti tingkat produktivitas, perputaran, kecelakaan, sikap dan biaya pengobatan karyawan, serta menunjukkan hubungannya dengan praktik-praktik SDM. Hal ini memberikan bukti bahwa departemen SDM penting bagi perusahaan, organisasi dan juga kelurahan.

Oleh karena hal tersebut, maka kami mengambil judul Pengenalan dan Pengembangan Kompetensi karyawan agar mencapai sasaran organisasi. Lokasi tempat kami melakukan pengabdian berada di kelurahan Rempoa. Kelurahan merupakan sarana pelayanan masyarakat yang fungsinya memberikan pelayanan dan bantuan kepada masyarakat sekitarnya. Untuk itu diperlukan karyawan yang cepat tanggap dan mampu memberikan jasanya secara tepat sasaran.

\section{RUMUSAN MASALAH}

Berdasarkan latar belakang diatas dapat dirumuskan permasalahan dalam pelaksanaan pengabdian masyarakat bagi karyawan kelurahan Rempoa adalah sebagai berikut:

1. Mengapa karyawan kelurahan Rempoa wajib mengembangkan kompetensinya?

2. Bagaimana cara mengembangkan kompetensi karyawan kelurahan Rempoa?

\section{TUJUAN PELAKSANAAN}

Tujuan pelaksanaan pengabdian msyarakat di Kelurahan Rempoa adalah:

1. Agar para karyawan kelurahan Rempoa mampu mengembangkan kompetensinya sebagai pelayan masyarakat.

2. Memberikan pengetahuan dan pelatihan kepada karyawan kelurahan Rempoa.

\section{TINJAUAN PUSTAKA}

\section{Kompetensi}

Menurut Suharsaputra, kompetensi adalah karakteristik utama dari individu untuk menghasilkan kinerja superior atau kinerja yang unggul pengetahuan dan keahlian. Oleh karena itu sumber daya manusia merupakan sumber kekuatan suatu organisasi untuk mencapai tujuannya. Apabila sumber daya manusia tersebut memiliki kompetensi yang handal dan relevan maka semua tugas pekerjaan akan mudah untuk dilakukan. Maka dari itu, pimpinan organisasi harus berupaya untuk mengembangkan kompetensi karyawan sesuai dengan desain pekerjaan dan rencana pengembangan usaha, baik untuk masa yang sekarang maupun untuk masa yang akan datang.

\section{Proses Pelatihan dan Pengembangan Kompetensi Karyawan}

Proses pelatihan dan pengembangan kompetensi karyawan seperti ADDIE (analysis, design, development, implementation, evaluation) atau analisis, perancangan, pengembangan, pelaksanaan dan evaluasi merupakan suatu sistem agar para karyawan dapat terlatih. Proses pelatihan dan pengembangan karyawan, dapat digambarkan sebagai berikut

a. Penilaian kebutuhan:

Analisis organisasi

Analisis individu

Analisis tugas 


\section{JURNAL ABDIMAS

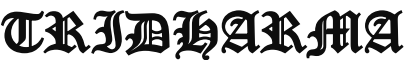

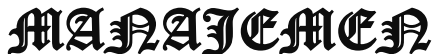

P-ISSN 2615-6849, E-ISSN 2622-3686

Jurnal ABDIMAS Vol. 1,No. 3,September 2020,Hal (28-32)

@Prodi Manajemen Fakultas Ekonomi Universitas Pamulang

Email: abdimasjurnal.unpam@gmail.com Telp: (021) 741-2566 b. Memastikan kesiapan para karyawan untuk pelatihan dan pengembangan:

$>$ Sikap-sikap dan motivasi

$>$ Keterampilan-keterampilan dasar

c. Menciptakan lingkungan pembelajaran:

$>$ Identifikasi tujuan-tujuan pembelajaran dan hasil-hasil pelatihan

$>$ Materi yang penuh arti

$>$ Praktik

$>$ Umpan balik

$>$ Pengamatan terhadap orang lain

> Mengatur dan mengordinasikan program

d. Memastikan pergantian pelatihan:

$>$ Strategi-strategi manajemen diri

$>$ Dukungan dari rekan kerja dan manajer

e. Memilih metode-metode pelatihan dan pengembangan:

$>$ Metode-metode presentasi

$>$ Metode-metode pengalaman praktis

Metode-metode kelompok

f. Mengevaluasi program-program pelatihan dan pengembangan:

> Identifikasi hasil-hasil pelatihan dan perancangan evaluasi

> Analisis biaya manfaat

Proses pelatihan dan pengembangan karyawan harus sistematis, tetapi cukup luwes untuk menyesuaikan diri dengan kebutuhan-kebutuhan perusahaan atau organisasi.

\section{METODE PELAKSANAAN}

Metode kegiatan ini berupa sosialisasi dan Pelatihan pengembangan karyawan, dengan cara yaitu:

1. Tahap Persiapan

Tahap persiapan yang dilakukan meliputi:

a. Survey awal, pada tahap ini dilakukan survei ke lokasi Kantor Kelurahan Rempoa di jalan Pahlawan, Ciputat Timur, Banten.

b. Pemantapan dan penentuan lokasi dan sasaran. Setelah survey maka ditentukan lokasi pelaksanaan dan sasaran peserta kegiatan.

c. Penyusunan bahan / materi sosialisasi pengenalan dan pengembangan karyawan suatu organisasi.

2. Tahap Pelaksanaan Penelitian

Tahap ini akan diberikan penjelasan mengenai pengenalan dan pengembangan karyawan suatu organisasi khususnya di kelurahan rempoa.

3. Tahap Penyuluhan

Untuk melaksanakan kegiatan tersebut digunakan beberapa metode penyuluhan yaitu:

a. Metode Ceramah

Metode ceramah dipilih untuk memberikan penjelasan tentang pentingnya mengembangkan kompetensi karyawan khususnya di kelurahan rempoa melalui slide, overhead projector dan video.

b. Metode Tanya Jawab

Metode tanya jawab sangat penting bagi para peserta pelatihan. Metode ini memungkinkan para peserta menggali pengetahuan sebanyakbanyaknya tentang cara mengembangkan kompetensi karyawan.

c. Metode Simulasi

Metode simulasi ini diberikan kepada para peserta penyuluhan dengan memberikan contoh melayani masyarakat untuk menangani masyarakat yang kehilangan KTP nya dan juga menangani proses bantuan dari pemerintah untuk membantu masyarakat yang terkena dampak Covid 19.

\section{HASIL DAN PEMBAHASAN}

Pengabdian Masyarakat yang diselenggarakan pada tanggal 20 April sampai dengan 22 April 2020 yang dilakukan oleh dosen-dosen Universitas 


\section{JURNAL ABDIMAS

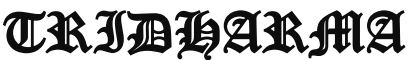

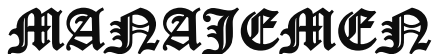

P-ISSN 2615-6849, E-ISSN 2622-3686

Jurnal ABDIMAS Vol. 1,No. 3,September 2020,Hal (28-32)

@ Prodi Manajemen Fakultas Ekonomi Universitas Pamulang

Email: abdimasjurnal.unpam@gmail.com Telp: (021) 741-2566
Pamulang yakni dengan cara memberikan penjelasan tentang kompetensi karyawan agar terus ditingkatkan sehingga karyawan dapat terus bekerja secara optimal demi kemajuan bersama khususnya kemajuan bagi karyawan kelurahan Rempoa untuk melayani kebutuhan masyarakatnya.

Proses pengembangan kompetensi dapat dilakukan dengan 5 (lima) langkah yaitu

1. Pengakuan kompetensi

Langkah utama dalam pengembangan kompetensi adalah mengakui kompetensi ketika kita melihatnya dan menghargai kontribusinya pada kinerja. Karyawan perlu diberikan pengetahuan mengenai kompetensi - kompetensi.

2. Memahami kompetensi

Memahami tipe-tipe situasi yang menuntut kompetensi sangat bermanfaat untuk meneliti situasi situasi dimana kompetensi itu ada dan membandingkan dengan situasi dimana kompetensi itu tidak ada.

3. Bereksperimen mendemonstrasikan kompetensi Salah satu tahap yang sangat penting dalam proses penguasaan kompetensi adalah kesempatan untuk mencoba perilaku-perilaku baru yang melibatkan usaha eksperimen dengan menggunakan cara-cara berpikir dan bertindak yang berbeda dari yang pernah dilakukan.

4. Berpraktik menggunakan kompetensi

Berpraktik menggunakan kompetensi dalam berbagai situasi. Reputasi dalam menggunakan kompetensi memberikan kepastian bahwa kompetensi tersebut benar benar nyata.

5. Menerapkan kompetensi dalam situasi-situasi kerja dan konteks yang lain

Pada langkah ini, individu harus mengintegrasikan kompetensi itu dengan kompetensi-kompetensi yang lain, seperti pikiran-pikiran dan perilaku-perilaku lain dalam situasi kerja yang nyata. Hal ini biasanya menuntut banyak praktik sementara dari individu yang bersangkutan untuk mengembangkan apresiasi yang lebih besar dengan kompetensi yang bersangkutan.

Semakin tepat penerapan kompetensi, maka hal tersebut dapat meningkatkan kualitas kompetensi karyawan. Kompetensi adalah pengetahuan, keahlian dan sifat yang dimiliki untuk menghasilkan kinerja yang unggul. Dengan diterapkannya kompetensi yang tepat maka dapat mengubah cara bekerja karyawan menjadi lebih kompeten.

\section{KESIMPULAN DAN SARAN \\ Kesimpulan}

Berdasarkan hasil pelaksanaan kegiatan pengabdian kepada masyarakat oleh Lembaga Penelitian dan Pengabdian Masyarakat (LPPM) dan Dosen Program Studi Magister Ekonomi Universitas Pamulang adalah sebagai berikut:

1. Setiap karyawan kelurahan Rempoa mengalami proses transformasi artinya setiap karyawan kelurahan Rempoa mengalami peningkatan kemampuan dalam melaksanakan tugas.

2. Sikap karyawan kelurahan Rempoa menjadi disiplin dan sesuai dengan etos keja.

3. Mampu meningkatkan penggunaan kecanggihan teknologi sehingga kecepatan untuk melayani masyarakat lebih cepat.

\section{Saran}

Berdasarkan hasil kesimpulan didapatkan beberapa saran sebagai berikut:

1. Untuk meningkatkan ketertarikan karyawan kelurahan Rempoa, maka diperlukan perubahan struktur kerja misalnya dengan melakukan perputaran pekerjaan (job rotation) yaitu sebuah 


\section{JURNAL ABDIMAS

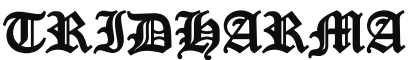

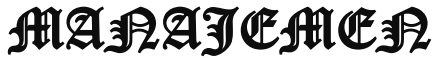

P-ISSN 2615-6849, E-ISSN 2622-3686

Jurnal ABDIMAS Vol. 1,No. 3,September 2020,Hal (28-32)

@ Prodi Manajemen Fakultas Ekonomi Universitas Pamulang

Email: abdimasjurnal.unpam@gmail.com Telp: (021) 741-2566 sistem perubahan pekerjaan dari salah satu tipe tugas ke tugas yang lainnya (yang disesuaikan dengan job description).

2. Mengadakan program yang mendukung, yang dirasakan dapat meningkatkan kepuasaan kerja karyawan kelurahan Rempoa seperti health center, profit sharing dan employee sponsored child care.

\section{DAFTAR PUSTAKA.}

Eko Suparno. (2014). Manajemen Pengembangan Sumber Daya Manusia, Jakarta: Ardadizya Jaya, 176-178.

Gerhart Barry, Hollenbeck John, Noe Raymond, Wright Patrick. (2013). Manajemen Sumber Daya Manusia Mencapai Keunggulan Bersaing, Jakarta: Salemba Empat, 8 -10.

Gusti Ayu Riska Riyanti, I Gede Adnyana Sudibya. (2012). Pengaruh Motivasi dan Kompetensi Terhadap Kinerja Karyawan Pada RSU Dharma Usadha, Fakultas Ekonomi Universitas Udayana, 622.

I Kadek Edy Sanjaya, Ayu Desi Indrawati. (2013). Pengaruh Kompetensi, Kompensasi dan Lingkungan Kerja Terhadap Kinerja Karyawan Pada PT. Pande Agung Segara Dewata, Fakultas Ekonomi Universitas Udayana, 220.

Pasaribu, V. L. D., Susanti, F., \& Hartuti, E. T. K. (2019). Memotivasi Siswa dan Siswi SMK Letris Indonesia di Dalam Menentukan Pilihan Untuk Melanjutkan Pendidikan Atau Bekerja Setelah Lulus Sekolah. Jurnal Pengabdian Dharma Laksana, 1(2), 161-172.

Pasaribu, V. L. D., Agrasadya, A., Shabrina, N., \& Krisnaldy, K. (2020). MENJADI ENTERPRENEUR MUDA YANG MEMILIKI JIWA LEADERSHIP UNTUK MENGHADAPI MASA DEPAN. Abdi Laksana, 1(1).

Pasaribu, V. L. D., Elburdah, R. P., Sudarso, E., \& Fauziah, G. (2020). PENGGUNAAN MANAJEMEN WAKTU TERHADAP
PENINGKATAN PRESTASI BELAJAR DI SMP ARAISIYAH. Jurnal ABDIMAS Tri Dharma Manajemen, l(1).

Pasaribu, V. L. D., Sulaiman, S., Sutiman, S., Thaharudin, T., \& Purnomo, B. Y. (2020). PENGENALAN LETAK POSYANDU TERDEKAT DIKELURAHAN PISANGAN DENGAN MANAJEMEN PEMASARAN REVOLUSI 4.0 UNTUK MENINGKATKAN PENGETAHUAN MASYARAKAT LETAK DAN FUNGSI POSYANDU TERDEKAT PADA KELURAHAN PISANGAN. DEDIKASI PKM, I(1), 105-110.

Pasaribu, V. L. D., Oktrima, B., Prabowo, B., Arianto, N., \& Haryoko, U. B. (2020). PROGAM PENDAMPINGAN DAN PENYELENGGARAAN PENDIDIKAN ANAK PADA USIA DINI TERHADAP PRESTASI BELAJAR DILINGKUNGAN RT 020 RW 009. KEL GIRI PENI. KEC WATES. YOGYAKARTA. JURNAL LOKABMAS KREATIF, 1(1), 71-75.

Sanjaya Wina. (2013). Strategi Pembelajaran Berorientasi Standar Proses Pendidikan, Jakarta: Kencana Prenadamedia group, 70.

Suharsaputra Uhar. (2013). Administrasi Pendidikan, Bandung: Refika Aditama, $214-230$.

Sunyoto Danang. (2013). Manajemen Sumber Daya Manusia. Yogyakarta: CAPS, $145-152$.

\section{DOKUMENTASI KEGIATAN}

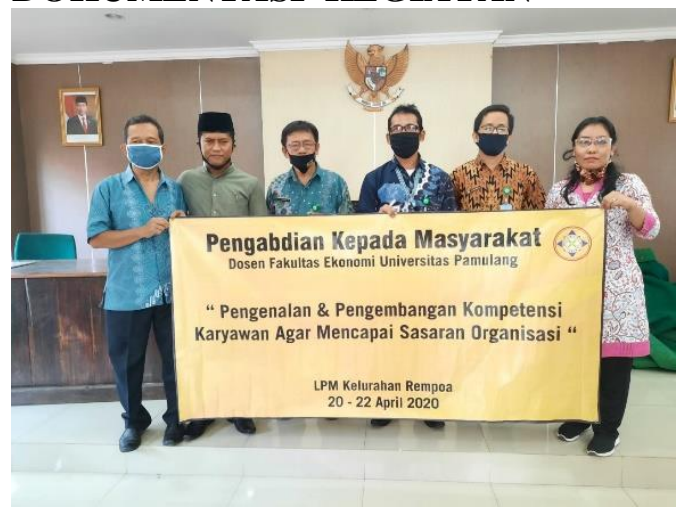

